\title{
Cognitive Assessment in Patients with Traumatic Brain Injury
}

\section{Instrumentos para avaliação cognitiva de pacientes com traumatismo cranioencefálico}

\author{
Ana Luiza Zaninotto ${ }^{1}$ Vinícius Monteiro de Paula Guirado ${ }^{2}$ Mara Cristina Souza De Lucia ${ }^{1}$ \\ Almir Ferreira de Andrade ${ }^{2}$ Manoel Jacobsen Teixeira ${ }^{2}$ Wellingson Silva Paiva ${ }^{2}$ \\ ${ }^{1}$ Division of Psychology, Hospital das Clínicas, Faculdade de Medicina, \\ Universidade de São Paulo (HC-FM-USP), São Paulo, SP, Brazil \\ ${ }^{2}$ Division of Neurosurgery, HC-FM-USP, São Paulo, SP, Brazil \\ Arq Bras Neurocir 2020;39(4):256-260 \\ Address for correspondence Wellingson Silva Paiva, MD, PhD, Divisão \\ de Neurocirurgia, Hospital das Clínicas, Faculdade de Medicina, \\ Universidade de São Paulo, São Paulo, SP, Brazil \\ (e-mail: wellingsonpaiva@yahoo.com.br).
}

\begin{abstract}
Traumatic brain injury (TBI) is a major public health problem in Western countries. ATBI brings many negative consequences, including behavioral and cognitive changes, which affect social adjustment and the performance of functional activities. Cognitive

Keywords

- traumatic brain injury

- cognition

- functional recovery

\section{Resumo}

Palavras-chave

- traumatismos encefálicos

- cognição

- recuperação funcional evaluation after TBI is a complex issue in what pertains to definition of the most appropriate questionnaires for clinical use in a comprehensive analysis of the condition of the patient. In this paper, we described a critical review of the main cognitive assessment tests currently used in clinical and research settings in patients with TBI.

O traumatismo cranioencefálico (TCE) é o maior problema de saúde pública nos países ocidentais. A ocorrência de um TCE traz diversas consequências negativas ao indivíduo, incluindo alterações comportamentais e cognitivas que afetam o ajustamento social e o desempenho em atividades funcionais. A avaliação das alterações cognitivas apresenta dificuldades de definição dos questionários e testes mais apropriados para análise ampla das condições do paciente para aplicação clínica. Neste artigo, realizamos uma revisão crítica dos principais testes de avaliação cognitiva utilizados atualmente, em ambiente clínico e de pesquisa, em pacientes com TCE.
\end{abstract}

\section{Introduction}

Traumatic brain injury (TBI) is the largest public health problem in the United States, with $\sim 235,000$ non-fatal hospitalizations annually; a total of 1.1 million of Americans with TBI are treated and discharged from the emergency department every year; $\sim 50,000$ of these patients die at the scene, and 20,000 perish during hospital care. ${ }^{1}$ Traumatic brain injury refers to brain damage, and it can be divided into open (penetrating, with skull and meninges perforation) and

received

June 9, 2016

accepted

July 4, 2016
DOI https://doi.org/

10.1055/s-0036-1594244. ISSN 0103-5355. closed TBI (contusions, concussions and diffuse axonal lesion). Open and closed traumas are distinguished by the nature of the lesion, as well as the underlying pathophysiological processes and associated cognitive changes. The highest TBI probability is observed in individuals between 15 and 24 years-old, with a 2:1 male predominance. Lower socioeconomic and educational levels and unemployment appear to be risk factors for increased likelihood of TBI and worse prognosis. Traumatic brain injury can be classified as mild, moderate, or severe, depending on the duration of
Copyright $\odot 2020$ by Thieme Revinter

Publicações Ltda, Rio de Janeiro, Brazil
License terms

(c) $(1) \$$ 
unconsciousness, the level of consciousness according to the Glasgow coma scale, and the presence of posttraumatic amnesia.

\section{Mechanisms of Neuronal Injury}

The evolution of closed-trauma TBI patients can be different from that of those patients with open trauma. In closed trauma, brain injury can occur in two stages: primary damage, beginning during impact; and secondary damage, which results from the physiological process triggered by the primary injury. These primary lesions result from white matter involvement, which is caused by rotational forces and/or acceleration/deceleration in the encephalic parenchyma, stretching and injuring axons. Lesion are usually multiple, predominating at the transition sites between white/ gray matter, and at the corpus callosum, hippocampus, dorsolateral aspect of the brainstem and the cerebellum, resulting in widespread cognitive dysfunctions-often related to the frontal lobes-and behavioral changes-including impulsivity, aggressiveness, depression and executive functions deficits, such as in planning, self-monitoring, impulse control, and volition. ${ }^{2}$

Mild TBI accounts for 10 to $15 \%$ of skull traumas, and it is followed by late symptoms (postconcussion syndrome). Diffuse axonal injury (DAI) is one of the most important causes of neurological sequelae in TBI patients. Although DAI usually results in clinical changes, abnormal findings are often not identified by conventional imaging techniques. ${ }^{3}$ Diffuse axonal injury is considered one of the most common types of primary neuronal injury in patients with severe head injury, ${ }^{4,5}$ although it may represent the end event of a TBI initially classified as mild. ${ }^{6}$ Although traumatic DAI results in axotomy (axon transection or disruption), this process is immediate only in areas sustaining major damage, most of which probably occur 12 to 24 hours after the initial trauma. ${ }^{7}$ Approximately one third of the patients who died after a TBI have spoken or obeyed orders before their death, suggesting that initial trauma alone is not lethal, although its consequences may be. ${ }^{8}$ These chronic DAI consequences usually cause global, cognitive, motor, sensory, and autonomic dysfunctions.

\section{Posttraumatic Brain Injury Cognitive Dysfunctions}

Mild TBIs are often more difficult to diagnose. This is due to the rapid resolution of acute signs and symptoms (e.g., loss of consciousness, posttraumatic amnesia, disorientation and confusion), as well as the typical absence of objective injury evidence from imaging tests. Although "minor" injuries are not given much thought, $\sim 15 \%$ to $30 \%$ of the patients are at risk of developing postconcussion syndrome (PCS). Postconcussion syndrome is a term used to describe the set of physical, cognitive and emotional symptoms associated with TBI. ${ }^{9}$ These symptoms can result in disability and suffering, and they can raise societal health costs. Despite scanty studies, there is a growing recognition that PCS is best understood in terms of biological, psychological and social interaction. Postconcussion syndrome is often self-limiting, but patients may have persistent symptoms, such as: (1) headache, (2) dizziness, (3) fatigue, (4) irritability, (5) insomnia, (6) problems with concentration, (7) memory difficulty and (8) stress, anxiety and depressive symptoms or alcohol intolerance. ${ }^{10}$ Postconcussion syndrome is deemed persistent when symptoms are sustained for more than 3 months.

A TBI has several negative consequences for the subject, including behavioral changes (inappropriate social behavior, depression, anxiety) and cognitive impairment (difficulty in perceiving deficits, memory changes, executive dysfunctions, language impairment), which affect social adjustment and performance in functional activities for long periods of time. Patients who have suffered severe trauma are often unable to return to work without some support. ${ }^{2}$ In addition, the impact of TBI affects family members, increasing the burden on caregivers and reducing the quality of life for all people, especially in more severe cases. Demographic characteristics, such as schooling, substance abuse, age at the time of trauma, type of work or profession are variables that may interfere with the return of the patient to the work routine, that is, the evolution for a better or worse prognosis. Some authors ${ }^{11}$ report that patients younger than 40 yearsold were more successful in returning to work, but others failed to show any correlation between age and a better prognosis after TBI. ${ }^{12}$ Gender does not seem to be a relevant factor in prognosis. ${ }^{13}$

Although TBI patients present transient neurological deficits, ${ }^{14}$ cognitive changes may be persistent, especially after moderate and severe lesions, and these include decreased mental flexibility and attention, shifting sets, alterations in planning, organization, sequencing, judgment, verbal fluency and operational memory, as well as impulsivity. Little et $\mathrm{al}^{15}$ analyzed 24 patients with mild and moderate TBI and found changes in executive function, attention and memory. The lesion type and severity, as well as the location of the focal lesion, are predictors of possible cognitive, behavioral, and psychosocial changes in these patients. However, given the variety of posttraumatic brain injury, and cognitive and behavioral changes, only a thorough neuropsychological examination can verify the individual characteristics of the dysfunctions of a patient, such as assessing whether verbal or visual spatial function is more impaired, and determining the presence of behavioral exacerbation or frontal inertia, and learning ability and mnemonic impairments. ${ }^{2}$

\section{Instruments to Evaluate the Functional and Cognitive Recovery of TBI Patients}

In 2010, the Liaison Federation and consultants for TBI projects formed a new group to build a set of recommendations to expand the definitions list, calling it common data elements ( $\mathrm{CDE}$ ). The CDE proposes the use of instruments to compare the outcomes of TBI studies-from demographic variables and clinical results across the whole spectrum of the condition-and to categorize such elements as basic, supplementary or emerging. ${ }^{16}$ The CDE makes specific recommendations for pediatric and military TBI groups, 
which will not be discussed here. The CDE is divided into modules, which, in turn, are grouped into categories:

(1) Characteristics of the participant/subject (e.g., demographic and social status characterization);

(2) Family history of the participant/subject (e.g., medical and family history);

(3) Events related to the disease/injury (e.g., classification and characterization of the disease);

(4) Evaluation and examinations (physical and neurological exams; vital signs; laboratorial tests and diagnostic imaging; treatment and intervention; results and summary of all recommended measures and outcomes; overall result; academic recommendations; skills and adaptations for daily life; functional behavior; cognitive activities limitations; communication disorders and deafness; exertion and vitality symptoms; physical functions; post-concussion and TCE-related symptoms; social cognition; neuropsychological impairments, among others).

The CDE recommends, specifically in the evaluations and exams module, some instruments to be used in neuropsychological evaluation, as well as scales and psychometric instruments for cognitive functions assessment. The suggested outcome measurements are the Glasgow Outcome Scale (GOS) ${ }^{17}$ and the Glasgow Outcome Scale Extended (GOSE), ${ }^{18}$ the Disability Rating Scale (DRS), ${ }^{19}$ and the Mayo-Portland Adaptability Inventory-4 (MPAI-4); ${ }^{20}$ however, these scales were not standardized for the Brazilian population. Other outcome measures scales, such as the Functional Independence Measure (FIM), ${ }^{21}$ the health survey SF-12, ${ }^{22}$ the Alcohol Use Disorders Identification Test: SelfReport Version (AUDIT) ${ }^{23}$ and the Alcohol, Smoking, and Substance Use Involvement Screening Test (ASSIST) ${ }^{24}$ have Brazilian validation.

To assess cognitive functions in adult patients with TBI, the CDE recommends some instruments, as listed in - Table $\mathbf{1}$.

There are few standardized instruments for the Brazilian population, as shown in - Table 1, which is a problem for the exclusive use of CDE-recommended instruments for cognitive evaluation of TBI patients in the clinical, research and diagnostic settings.

Tests like those suggested by the CDE may be an option to aid a more accurate diagnostic evaluation. To evaluate episodic visual spatial memory learning, the CDE recommends the Brief Visuospatial Memory Test-Revised (BVMT-R), in which consists of six simple and distinct geometric figures distributed as a matrix on a sheet of paper. The matrix is displayed for 10 seconds and withdrawn; then, the patient is asked to reproduce the figures, considering both their location on the sheet and their graphic characteristics. This same procedure is repeated two more times, and, after 25 seconds, the late recall is requested. After the late recall, the previously learned figures are recognized, among other six new figures. Rey's Complex Figure, a recognized and approved test for clinical use, consists of a copy and memory test of complex geometrical figures, and it can be used as a measure

Table 1 Common data elements classification per traumatic brain injury study type, relevant population, and recommendations of outcome measurements for cognitive impairments

\begin{tabular}{|c|c|c|c|}
\hline Instruments for outcome measurements & $\begin{array}{l}\text { Acute } \\
\text { hospitalization }\end{array}$ & $\begin{array}{l}\text { Moderate/severe } \\
\text { rehabilitation }\end{array}$ & Mild concussion/TBI \\
\hline Automated Neuropsychological Assessment Metrics (ANAM)* & Supplementary & Supplementary & Supplementary \\
\hline Brief Visuospatial Memory Test-Revised (BVMT-R)* & Supplementary & Supplementary & Supplementary \\
\hline Color-Word Interference Test* & Supplementary & Supplementary & Supplementary \\
\hline Controlled Oral Word Association Test (COWAT)* & Supplementary & Supplementary & Supplementary \\
\hline Grooved Pegboard Test* & Supplementary & Supplementary & Supplementary \\
\hline NIH Toolbox Cognitive Battery* & Supplementary & Supplementary & Supplementary \\
\hline Rey Auditory Verbal Learning Test (RAVLT)** & Basic & Basic & Basic \\
\hline Symbol Digit Modalities Test* & Supplementary & Supplementary & Supplementary \\
\hline Trail Making Test (TMT)* & Basic & Basic & Basic \\
\hline $\begin{array}{l}\text { Wechsler Adult Intelligence Scale } \\
\text { (WAIS-IV), Digit Span subtest*** }\end{array}$ & Supplementary & Supplementary & Supplementary \\
\hline $\begin{array}{l}\text { Wechsler Adult Intelligence Scale } \\
\text { (WAIS-IV), Letter-Number Sequencing subtest*** }\end{array}$ & Supplementary & Supplementary & Supplementary \\
\hline $\begin{array}{l}\text { Wechsler Adult Intelligence Scale } \\
\text { (WAIS-IV), Processing speed factorial index }\end{array}$ & Basic & Basic & Basic \\
\hline $\begin{array}{l}\text { Word Reading Subtest of the Wide Range } \\
\text { Achievement Test (WRAT-4)* }\end{array}$ & Supplementary & Supplementary & Supplementary \\
\hline
\end{tabular}

Abbreviations: NIH, National Institutes of Health; TBI, traumatic brain injury.

Source: http://www.commondataelements.ninds.nih.gov/tbi.aspx\#tab=Data_Standards.

${ }^{*}$ Test without Brazilian standardization.

${ }^{* *}$ Test adapted for the Brazilian population (without the validation of CRP).

${ }^{* * *}$ Test with Brazilian standardization (WAIS-III, since WAIS-IV has not been released yet). 
of episodic memory and visual constructive planning. Although these are tests assessing broad visual spatial episodic memory, numerous other measures are distinct and peculiar to each evaluation instrument.

The most commonly used trail test for attention and cognitive functioning processes assessment, also recommended by the CDE, is the Trail Making Test (TMT). The test is divided into two portions: the first one (TMT A) involves simple visual search and motor speed; the second one (TMT B) demands a more complex visual search as a function of stimuli change, involving the executive functions performance. A test analogous to the TMT is the Color Trail Test (CTT), which was adapted for the Brazilian population. Although the first portion of the test demands cognitive aspects, similar to TMT A, the second portion of the color trail test is more demanding compared with TMT B (see adapted manual in Rabelo et al, 2010); thus, the use of both TMT and CTT may be an interesting option for neuropsychological evaluation.

The Rey Auditory Verbal Learning Test (RAVLT) was adapted to the Brazilian population, and, over time, other studies were performed to adapt tests to specific Brazilian populations, such as the elderly. ${ }^{25}$ The RAVLT consists of a list of 15 words that are read by the examiner; next, the patient is asked to repeats as many words as he/she can remember. This same procedure is repeated 4 more times, and, after 25 seconds, the late recall is requested. Late recognition of previously learned words is also performed. RAVLT is not standardized for the Brazilian population and, to date, it has not received a favorable opinion by the Brazilian Federal Council of Psychology for clinical use.

The tests below are not standardized for the Brazilian population. Their use in research requires caution during results interpretation.

- Automated Neuropsychological Assessment Metrics (ANAM): a computerized test that assesses speed and accuracy of attention, memory and thinking ability.

- Color-Word Interference Test: a test assessing attention, executive functioning and inhibitory control.

- Controlled Oral Word Association Test (COWAT): a test to assess verbal fluency and executive functioning.

- Grooved Pegboard Test: it assesses fine motor skills and coordination.

- National Institutes of Health (NIH) Toolbox Cognitive Battery: it consists in a battery for executive functions, attention, episodic memory, language, processing speed and operational memory evaluation.

- Symbol Digit Modalities Test: it assesses processing speed.

- Word Reading Subtest of the Wide Range Achievement Test (WRAT-4): it provides a basic measure of reading, spelling, comprehension, and mathematical academic skills.

\section{Conclusion}

Traumatic brain injury patients represent a challenge for acute and chronic care. The evaluation of functional recovery and cognitive alterations is difficult because of the definition of the most appropriate questionnaires and tests for a broad analysis of the patient's conditions, both for clinical and research application. The tests suggested by the CDE may be used, but their limitations should be considered due to the lack of validation of international instruments for our population. It is suggested, whenever possible, to include similar standardized tests, such as the factorial processing rate (Weschler scales-WAIS-III), which aid in the interpretation, diagnosis and better management of the patient and his/her family.

\section{Conflict of Interests}

The authors have no conflict of interests to declare.

\section{References}

1 Corrigan JD, Selassie AW, Orman JA. The epidemiology of traumatic brain injury. J Head Trauma Rehabil 2010;25(02):72-80

2 Lezak MD, Howieson DB, Bigler ED, Tranel D. Neuropsychological assessment. 5 ed. New York, NY: Oxford University Press; 2012

3 Kraus MF, Susmaras T, Caughlin BP, Walker CJ, Sweeney JA, Little DM. White matter integrity and cognition in chronic traumatic brain injury: a diffusion tensor imaging study. Brain 2007;130(Pt 10):2508-2519

4 Adams JH, Graham DI, Murray LS, Scott G. Diffuse axonal injury due to nonmissile head injury in humans: an analysis of 45 cases. Ann Neurol 1982;12(06):557-563

5 Gentry LR, Godersky JC, Thompson BH. Traumatic brain stem injury: MR imaging. Radiology 1989;171(01):177-187

6 Topal NB, Hakyemez B, Erdogan C, et al. MR imaging in the detection of diffuse axonal injury with mild traumatic brain injury. Neurol Res 2008;30(09):974-978

7 Meythaler JM, Peduzzi JD, Eleftheriou E, Novack TA. Current concepts: diffuse axonal injury-associated traumatic brain injury. Arch Phys Med Rehabil 2001;82(10):1461-1471

8 Reilly PL. Brain injury: the pathophysiology of the first hours.'Talk and Die revisited'. J Clin Neurosci 2001;8(05):398-403

9 King NS, Kirwilliam S. Permanent post-concussion symptoms after mild head injury. Brain Inj 2011;25(05):462-470

10 Organization WWH. International Classification of Diseases (ICD). 2010

11 Ponsford JL, Olver JH, Curran C, Ng K. Prediction of employment status 2 years after traumatic brain injury. Brain Inj 1995;9(01): $11-20$

12 Fabbri A, Servadei F, Marchesini G, Stein SC, Vandelli A. Observational approach to subjects with mild-to-moderate head injury and initial non-neurosurgical lesions. J Neurol Neurosurg Psychiatry 2008;79(10):1180-1185

13 Husson EC, Ribbers GM, Willemse-van Son AHP, Verhagen AP, Stam HJ. Prognosis of six-month functioning after moderate to severe traumatic brain injury: a systematic review of prospective cohort studies. J Rehabil Med 2010;42(05):425-436

14 Lima DPD, Simão Filho C, Abib SdeC, de Figueiredo LFP. Quality of life and neuropsychological changes in mild head trauma. Late analysis and correlation with S100B protein and cranial CT scan performed at hospital admission. Injury 2008;39(05):604-611

15 Little DM, Kraus MF, Joseph J, et al. Thalamic integrity underlies executive dysfunction in traumatic brain injury. Neurology 2010; 74(07):558-564

16 Maas AI, Harrison-Felix CL, Menon D, et al. Common data elements for traumatic brain injury: recommendations from the interagency working group on demographics and clinical assessment. Arch Phys Med Rehabil 2010;91(11):1641-1649

17 Jennett B, Snoek J, Bond MR, Brooks N. Disability after severe head injury: observations on the use of the Glasgow Outcome Scale. J Neurol Neurosurg Psychiatry 1981;44(04):285-293

18 Wilson JTL, Pettigrew LEL, Teasdale GM. Structured interviews for the Glasgow Outcome Scale and the extended Glasgow Outcome 
Scale: guidelines for their use. J Neurotrauma 1998;15(08): 573-585

19 Rappaport M, Hall KM, Hopkins K, Belleza T, Cope DN. Disability rating scale for severe head trauma: coma to community. Arch Phys Med Rehabil 1982;63(03):118-123

20 Malec JF. The Mayo-Portland Participation Index: A brief and psychometrically sound measure of brain injury outcome. Arch Phys Med Rehabil 2004;85(12):1989-1996

21 Riberto M, Miyazaki MH, Jucá SSH, Sakamoto H, Novazzi Pinto PP, Battistella LR. Validação da Versão Brasileira da Medida de Independência Funcional. Acta Fisiatrica 2004;11(02):72-76

22 Andrade TL, Camelier AA, Rosa FW, Santos MP, Jezler S, Pereira e Silva JL. Applicability of the 12-Item Short-Form Health Survey in patients with progressive systemic sclerosis. J Bras Pneumol 2007;33(04):414-422

23 Lima CT, Freire ACC, Silva APB, Teixeira RM, Farrell M, Prince M. Concurrent and construct validity of the audit in an urban brazilian sample. Alcohol Alcohol 2005;40(06):584-589

24 Henrique IF, De Micheli D, Lacerda RB, Lacerda LA, Formigoni ML. [Validation of the Brazilian version of Alcohol, Smoking and Substance Involvement Screening Test (ASSIST)]. Rev Assoc Med Bras (1992) 2004;50(02):199-206

25 Malloy-Diniz LF, Lasmar VA, Gazinelli LdeS, Fuentes D, Salgado JV. The Rey Auditory-Verbal Learning Test: applicability for the Brazilian elderly population. Br J Psychiatry 2007;29(04): 324-329 